\title{
Behandling av lårhalsbrudd
}

\begin{abstract}
Sammendrag
Bakgrunn. Lårhalsbrudd rammer ca. 5000 årlig i Norge. Gjennomsnittsalderen er 83 år og ca. $75 \%$ er kvinner. I over 50 år har det vært diskusjon om osteosyntese, med skruer eller nagler, eller protese er beste behandling av lårhalsbrudd med feilstilling. Tradisjonen i Norge har vært osteosyntese. Resultater fra nyere studier støtter bruken av protese. Vi vil gi en oversikt over kunnskapen om behandlingen av lårhalsbrudd med vekt på nyere studier.
\end{abstract}

Materiale og metode. Artikkelen er basert på ikke-systematisk gjennomgang av artikler i Medline.

Resultater. Osteosyntese med skruer eller nagler av brudd med feilstilling hos eldre gir en risiko for reoperasjon på grunn av komplikasjoner hos $30-40 \%$ av pasientene, mot ca. $10 \%$ ved protese. Protese gir bedre funksjonelt resultat for eldre med brudd med feilstilling. Hemiprotese er vanligst, men noen data tyder på at friske, relativt unge (under 75-80 år) kan få det bedre med totalprotese. Unge lunder 60-65 år), friske pasienter skal behandles med osteosyntese, men ca. $30 \%$ opplever manglende tilheling eller nekrose av caput femoris. Pasienter med lårhalsbrudd $\mathrm{i}$ anatomisk stilling behandles også med osteosyntese, uansett alder, og risikoen for behandlingssvikt er ca. $10 \%$.

Fortolkning. Eldre med lårhalsbrudd med feilstilling bør behandles med protese, vanligvis hemiprotese. Osteosyntese er stort sett reservert for pasienter med brudd uten feilstilling og for unge, ellers friske pasienter.

\section{Frede Frihagen}

j.f.frihagen@medisin.uio.no

Ortopedisk avdeling

Oslo universitetssykehus, Ullevål

0407 Oslo

og

Medisinsk fakultet

Universitetet i Oslo

\section{Wender Figved}

Ortopedisk avdeling

Sykehuset Asker og Bærum

og

Medisinsk fakultet

Universitetet i Oslo

\section{Jan Erik Madsen}

Ortopedisk avdeling

Oslo universitetssykehus, Ullevål og

Medisinsk fakultet

Universitetet i Oslo

\section{Cathrine M. Lofthus}

Endokrinologisk senter

Oslo universitetssykehus, Aker og

Medisinsk fakultet

Universitetet i Oslo

Ragnhild Øydna Støen
Lars Nordsletten
Ortopedisk avdeling
Oslo universitetssykehus, Ullevål
og
Medisinsk fakultet
Universitetet i Oslo

Norge har verdens høyeste forekomst av osteoporotiske brudd (1-3). Det er ca. 10000 hoftebrudd hvert år. $55 \%$ av disse er lårhalsbrudd (2). Gjennomsnittsalderen for pasientene er om lag 83 år og ca. $75 \%$ er kvinner (2-8). Insidensen av hoftebrudd er ikke lenger økende, men en økning i totalt antall lårhalsbrudd kan likevel forventes, siden antallet eldre øker (2). Bare ca. $4 \%$ av pasientene er under 60 år, og de fleste av disse har en eller flere risikofaktorer for lav beintetthet og/eller falltendens og kan fremstå som «fysiologisk gamle» $(2,9)$. For eldre med lårhalsbrudd er dødeligheten etter ett år ca. $25 \%(6,7,10)$. De som i utgangspunktet er friske og oppegående har imidlertid ikke økt dødelighet sammenliknet med jevnaldrende uten brudd (11). Et lårhalsbrudd er uansett en dramatisk begivenhet for den som rammes og innebærer en risiko for tap av funksjon og økt avhengighet $(6,7$, $10)$.

Det er allmenn enighet om at lårhalsbrudd skal opereres. Ved brudd uten feilstilling er det enighet om at behandlingen skal være skruer eller nagler. For brudd med feilstilling, derimot, har det blant norske ortopeder vært en langvarig, og tidvis intens, diskusjon om hvorvidt osteosyntese av bruddet med skruer eller nagler eller med protese er best behandling. I Norge har osteosyntese dominert, men de siste årene har det også hos oss skjedd en endring i retning av mer bruk av primær protese. I 2005-06 ble 55 \% av lårhalsbrudd med feilstilling operert med protese ifølge Nasjonalt hoftebruddregister, herav $51 \%$ med hemiprotese $(4,10)$. Målet med denne artikkelen er å gi en oversikt over kunnskapen om kirurgisk behandling av lårhalsbrudd og basert på dette komme med behandlingsanbefalinger.

\section{Materiale og metode}

Oversiktsartikler, systematiske gjennomganger, metaanalyser og øvrig relevant litteratur ble identifisert ved ikke-systematiske søk i Medline. Randomiserte studier og metaanalyser av disse finnes når det gjelder lårhalsbrudd med feilstilling hos eldre. For behandling av andre pasientgrupper er rådene basert på pasientserier og ikke-randomiserte sammenlikninger.

Klinikk, diagnostikk og klassifisering Skademekanismen ved lårhalsbrudd er vanligvis et fall med direkte traume mot trochanterregionen. Ved feilstilling i bruddet vil underekstremiteten typisk være forkortet og utadrotert. Pasienten kan vanligvis ikke belaste beinet og det vil være smerter ved bevegelse og ømhet ved press på trochanter major $(5,12)$. Konvensjonell røntgen vil gi diagnosen i over $95 \%$ av tilfellene, men ved

\section{Hovedbudskap}

- Eldre pasienter med lårhalsbrudd med feilstilling bør behandles med protese, som regel hemiprotese

- Pasienter med brudd i anatomisk stilling kan behandles med osteosyntese, uansett alder

- Unge, friske pasienter bør behandles med osteosyntese uavhengig av grad av feilstilling

- Pasienter med brudd på grunn av metastaser eller brudd i hofteledd med symptomgivende leddsykdom bør opereres med protese 
negativt eller vanskelig tolkbart røntgenbilde vil MR, eventuelt CT, kunne brukes (13). Det finnes flere forskjellige klassifiseringer av lårhalsbrudd som har det til felles at de ikke bør brukes, fordi de verken er reproduserbare eller gir føringer for behandling eller prognose. En todeling i brudd med og uten feilstilling (dislokert eller udislokert) har imidlertid vist seg å være nyttig $(5,12,14)$

\section{Behandlingsalternativer}

Konservativ behandling

Konservativ behandling inkluderer gipsing, strekkbehandling, sengeleie eller mobilisering på krykker. Ingen av disse alternativene har noen plass i rutinebehandlingen av pasienter med lårhalsbrudd $(5,12,15)$. Også brudd $\mathrm{i}$ anatomisk stilling, inkludert brudd påvist ved hjelp av MR eller CT, bør opereres. Det vil forenkle rehabiliteringen og man unngår sekundær dislokasjon. Uten operasjon vil sekundær dislokasjon skje i $20 \%$ av tilfellene $(16,17)$

\section{Osteosyntese}

Det finnes over 100 forskjellige implantater for osteosyntese av lårhalsbrudd, men ingen er dokumentert bedre enn andre (18). Ved osteosyntese brukes det i Norge vanligvis to parallelle skruer eller nagler (4). Skruene eller naglene settes parallelt i lårhalsen, og en sammensynkning tillates for å komprimere i bruddet og med det øke sjansen for tilheling. Skruer er derfor gjenget bare i den delen som skal stå i caput femoris. To skruer eller nagler brukes for å hindre rotasjon (fig 1). Kvaliteten på reposisjonen er nok av større betydning enn typen skruer og nagler og deres plassering $(18,19)$. Forekomsten av osteosyntesesvikt er imidlertid nokså lik fra studie til studie, uavhengig av operasjonsmetode, type implantat og kirurgenes erfaring (6, 20-24). Selv med tilhelede brudd endres ofte anatomien og mekanikken i hofteleddet, særlig med forkorting av lårhalsen, slik at pasienten ikke får «sitt eget hofteledd» tilbake $(6,25)$.

Udislokerte lårhalsbrudd behandles med osteosyntese. Forekomsten av manglende tilheling og nekrose av caput femoris er $5-15 \%$. De funksjonelle resultatene er akseptable, men $25 \%$ av pasientene oppgir varige plager $(8,25,26)$.

Hos unge (<60-65 år), for øvrig friske pasienter behandles også brudd med feilstilling med osteosyntese. De er i en alder der det er en fordel å utsette en eventuell proteseoperasjon så lenge som mulig fordi de har høye funksjonelle krav og fordi en protese har begrenset levetid. Dessuten har en revisjonsoperasjon med bytte av protese en noe høyere risiko for dårlig resultat enn første operasjon. De unge pasientene har en noe lavere forekomst av osteosyntesesvikt enn eldre, men dette oppveies nesten helt av en høyere forekomst av avaskulær nekrose av caput femoris. En metaanalyse av pasient- serier med pasienter i alderen $16-50$ år viste $9 \%$ osteosyntesesvikt og $23 \%$ avaskulær nekrose. Det var noe mer komplikasjoner ved brudd med feilstilling (27). Det vanlige er å reponere bruddet lukket med røntgengjennomlysning. Åpen reposisjon anbefales der man ikke får et godt resultat med lukket teknikk, fordi en best mulig stilling av bruddet er viktig for tilheling og senere hoftefunksjon $(8,12)$.

Osteosyntese kan i tillegg en sjelden gang være aktuelt som palliativ behandling hos svært syke eldre med kort forventet levetid. Operasjonen gjøres da med tanke på smertelindring og hjelp ved stell og pleie (5).

\section{Protese}

Det skilles mellom hemiprotese og totalprotese. Ved en hemiprotese erstattes caput og collum femoris med en protese, mens acetabulum forblir urørt. I en bipolar hemiprotese er det et internt ledd i protesen, slik at en del av bevegelsen kan foregå der. I en unipolar hemiprotese foregår all bevegelse mellom protesehodet av metall og pasientens egen brusk i acetabulum. Ved totalprotese settes det også en protesedel i acetabulum. I Norge brukes bipolare hemiproteser i over $90 \%$ av primære proteseoperasjoner ved akutt lårhalsbrudd, og over $90 \%$ av disse igjen er sementerte (fig 1) $(4,10)$.

De tre viktigste komplikasjonene ved proteseoperasjon er luksasjoner, infeksjoner og brudd rundt protesen. Luksasjoner forekommer i ca. $4 \%$ for hemiproteser og om lag det dobbelte for totalproteser $(23,24)$. Faren for luksasjon av en totalprotese er mindre ved bruk av et stort leddhode på protesen (32 $\mathrm{mm}$ eller større) (28). Alvorlige postoperative infeksjoner forekommer i ca. $2 \%$ av tilfellene (23). Brudd rundt protesen forekommer hos omtrent $3 \%$, muligens noe mindre ved sementerte proteser (23). Spørsmålet om sementering eller ikke har ikke noe entydig svar. Innsettelse av en usementert protese tar 10-15 minutter kortere tid og gir mindre blødning enn en sementert (7). Cochranes metaanalyse viste en tendens til mindre smerter ved sementerte proteser (29), og i en annen metaanalyse fant man lavere reoperasjonsrate enn ved usementerte proteser (30). Dette bildet kan riktignok endres med bruk av moderne, anatomiske usementerte proteser, som har overflater og belegg som gir rask og solid kontakt mellom bein og protese $(7,8,31)$. Det er også rapportert at risikoen for peroperative dødsfall er høyere ved bruk av sementerte proteser (32). Alvorlige sementreaksjoner er imidlertid meget sjelden. Slitasje i acetabulum er en potensiell fare ved hemiproteser, men i praksis er dette et lite problem, spesielt ved bruk av bipolare proteser. Proteseløsning er likeledes sjelden for pasienter operert med protese etter lårhalsbrudd $(6,7,23,29)$.

Eldre med brudd med feilstilling er den største gruppen (75\%) av pasienter med lårhalsbrudd. Vi kjenner til 19 randomiserte studier der man sammenlikner protese og osteosyntese hos disse pasientene $(6,22$, 33-49). De fleste studiene sammenlikner osteosyntese med enten hemiprotese $(6,34$, $43,49)$ eller totalprotese $(33,35,39,42,44)$, mens noen inkluderer begge protesetyper

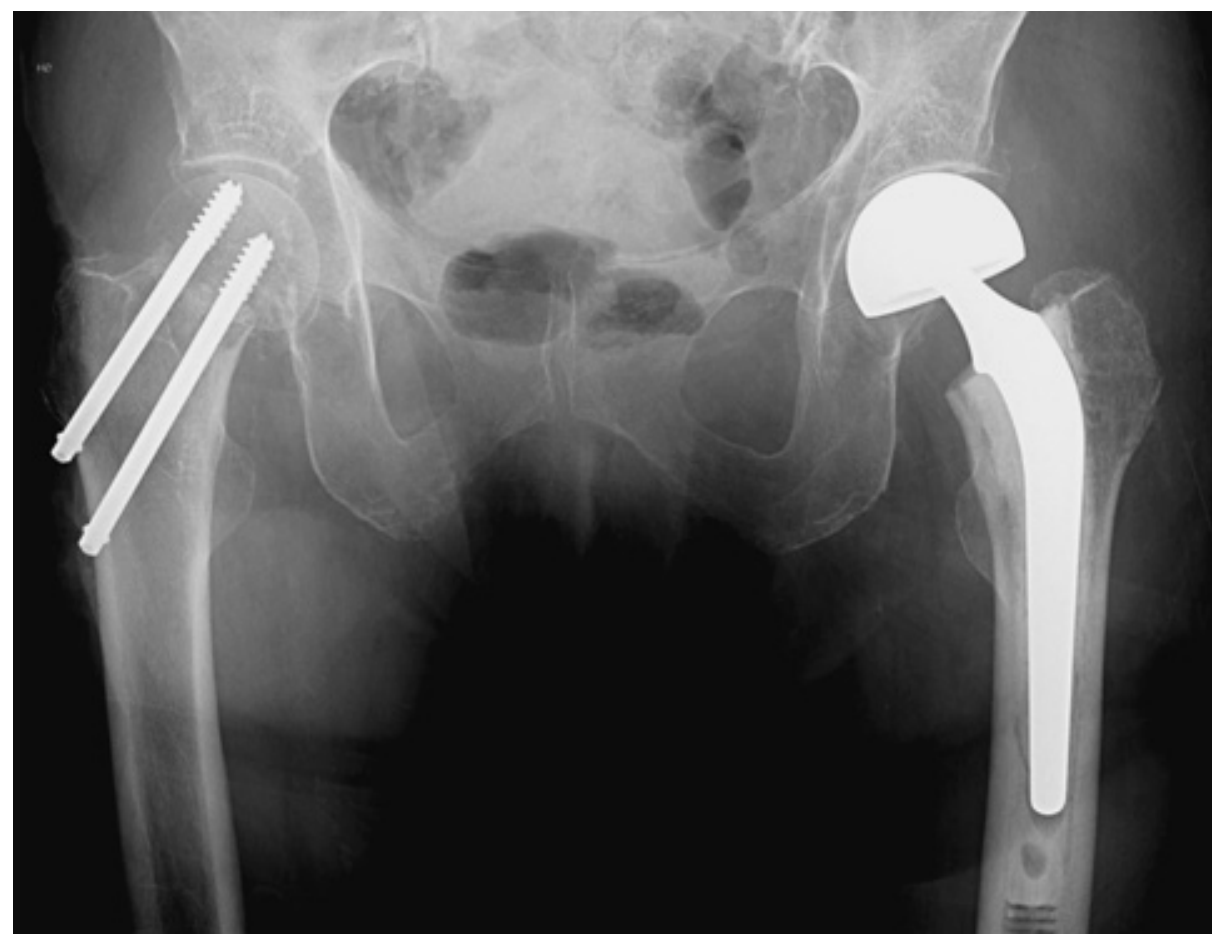

Figur 1 Pasient med bilaterale lårhalsbrudd. På venstre side har hun en bipolar sementert Charnley/ Hastings hemiprotese. På høyre side har hun to parallelle Olmed-skruer. Skruene er gjenget bare i caputdelen for å tillate kompresjon over bruddet. Skruene mistet taket etter noen uker og hun fikk hemiprotese også på høyre side (5). (c) 2009. Gjengitt med tillatelse fra Taylor \& Francis 
(36-38, 50). Den nedre aldersgrensen er 60-75 år. Det foreligger tre metaanalyser basert på de randomiserte studiene $(20,23$, 24). Forekomsten av reoperasjoner er gjennomgående $30-40 \%$ etter osteosyntese og $10 \%$ eller lavere etter proteseinnsetting. I de tre metaanalysene er det ingen forskjell i sykelighet eller dødelighet mellom gruppene. I to av metaanalysene ses heller ingen forskjell i funksjonelle resultater, mens i Cochranes metaanalyse beskrives en tendens til mindre smerter og bedre funksjon i hofteleddet ved innsetting av sementerte proteser enn ved osteosyntese (23). Studiene er publisert over et tidsrom på nesten 30 år, og det er en tendens til at de nyere studiene er av høyere kvalitet $(6,22,33,34,36,37)$ og at de viser bedre funksjonelle resultater i protesegruppen $(6,33,36,37)$.

Noen hevder at skrueosteosyntese er et godt alternativ hos de aller eldste fordi det er færre reoperasjoner enn hos yngre. Dataene er dog ikke entydige. Inntrykket av at det er færre komplikasjoner ved osteosyntese hos de eldste kan skyldes at disse ikke blir reoperert, til tross for komplikasjoner $(14,15,22)$. Det er heller ikke sannsynlig at pasienter med kognitiv svikt har noen fordel av osteosyntese $(5,10,34,40)$. Vi anbefaler ikke noen øvre aldersgrense eller «sykelighetsgrense» for protesekirurgi.

I Norge er det ingen sterk tradisjon for primærbehandling med totalprotese (51). Metaanalysen fra Cochrane-samarbeidet (29) viser ingen sikre forskjeller mellom hemiprotese og totalprotese, men det pekes på tre nyere studier som viser at relativt sett unge og spreke eldre med lårhalsbrudd kan oppnå bedre funksjon med totalprotese $(21$, 37,52 ). I valget mellom hemiprotese og totalprotese må mulig bedre funksjon ved totalprotese veies mot mulige ulemper ved et større inngrep og at det i flere studier ses en $ø k t$ tendens til luksasjoner $(24,29,35,51)$. Totalprotese etter lårhalsbrudd bør opereres av en erfaren protesekirurg for å holde komplikasjonsfrekvensen, spesielt luksasjonsfrekvensen, så lav som mulig (33).

Pasienter med risiko for dårlig bruddtilheling, uansett alder og feilstilling, behandles med protese. Pasienter med alvorlig giktsykdom eller annen symptomgivende leddpatologi behandles også med protese. Totalprotese er mest aktuelt ved uttalte forandringer i hofteleddet. Protese er også anbefalt ved brudd i patologisk bein, som vanligvis er brudd gjennom metastaser. Pasientene vil ofte ha hatt økende smerter og redusert gangfunksjon i tiden før bruddet, og røntgenbildet vil gi mistanke om patologisk beinvev. Disse bruddene har ingen mulighet til å tilhele. Sementert protese er derfor anbefalt behandling $(5,8)$. Brudd gjennom primære tumorer, både benigne og maligne, eller brudd ved annen beinpatologi er sjelden. Ved primære maligne tumorer vil oftest et stort område med bein og bløtdeler fjernes og en spesialprotese settes inn (53).

\section{Perioperativ behandling}

Væskebehandling, smertebehandling og forebygging av delirium starter allerede ved innleggelsen. Medikamentell tromboseprofylakse kan være av verdi, og lavmolekylært heparin er vist å forebygge dyp venetrombose. God hydrering, mobilisering og støttestrømper vil også kunne forebygge venetrombose. Ingen tiltak mot trombose er imidlertid vist å redusere dødelighet eller forekomsten av alvorlige lungeembolier ved lårhalsbrudd. Spinalbedøvelse er sannsynligvis bedre enn narkose. Antibiotikaprofylakse anbefales peroperativt og det første postoperative døgnet ved protesekirurgi. De fleste postoperative komplikasjoner forebygges ved tidlig mobilisering, og pasientene mobiliseres med belastning så fort som mulig. Unge pasienter operert med osteosyntese får imidlertid vanligvis restriksjoner på belastning den forste tiden $(5,8,12,54$, $55)$.

\section{Hvor viktig er ventetid?}

Ventetid før kirurgi har vært mye diskutert, og det har vært et credo at man skal operere disse pasientene så fort som overhodet mulig. De nyeste og beste studiene tyder på at det ikke er noen grunn til å forsere inngrepet innen de første 24 timene. Snarere er det argumenter for å ta seg tid til å utrede og behandle pasienten, for eksempel korrigere væske- og elektrolyttforstyrrelser, for deretter å operere på dagtid med uthvilt og kompetent personale. Dog kan det se ut som at en ventetid på over to døgn er uheldig (56-60). Uansett er det dårlig service å la pasienter ligge i kø med brukket lårhals, og for de færreste pasienter kan det argumenteres for å vente lenger enn til neste dag med operasjon.

\section{Konklusjon}

Begrepet «den uløste frakturen» har vært brukt om lårhalsbrudd, spesielt fordi resultatene ved osteosyntese er dårligere enn ved andre brudd (61). De siste årene har vi kommet et stort skritt nærmere en løsning. Eldre med brudd med feilstilling utgjør det store flertallet av disse pasientene og de skal behandles med protese, vanligvis hemiprotese. Det er under $10 \%$ komplikasjonsrisiko, og hoftefunksjonen blir bedre enn etter skrueeller naglefiksering. Denne anbefalingen er forankret i metaanalyser og randomiserte studier av høy kvalitet. Noen få randomiserte studier gir videre holdepunkter for at relativt unge og spreke pasienter kan ha ytterligere fordel av å bli operert med totalprotese. Brudd i helt anatomisk stilling behandles med skrueosteosyntese, uansett pasientens alder. Også disse pasientene har en risiko for varige smerter og redusert gangfunksjon på $25 \%$ og en risiko for manglende tilheling eller nekrose av caput femoris på $5-15 \%$. Unge (under 60-70 år), friske pasienter behandles med osteosyntese, men må informeres om at det er ca. $30 \%$ risiko for manglende tilheling eller nekrose av caput femoris. Unge pasienter med høy «fysiologisk alder» bør vurderes for primær hemiprotese. Brudd i patologisk bein og brudd ved symptomatisk leddsykdom behandles med protese.

Oppgitte interessekonflikter: Ingen av forfatterne har fått betaling eller annen motytelse for å skrive denne artikkelen. Følgende forfattere har mottatt ytelser fra produsenter og leverandører av implantater som brukes $i$ behandlingen av lårhalsbrudd: Frede Frihagen: Forskningsmidler og konsulenthonorar fra OrtoMedic, reisestøtte fra Smith \& Nephew, reisestøtte fra Synthes og forelesningshonorar fra Stryker Norge. Wender Figved: Forelesningshonorar og reisestøtte fra OrtoMedic, reisestøtte fra Stryker Norge og B. Braun Medical og forskningsmidler fra Smith \& Nephew. Jan Erik Madsen: Forskningsmidler, reisestøtte og forelesningshonorar fra Smith \& Nephew, reisestøtte fra Synthes, Stryker Norge og OrtoMedic. Lars Nordsletten: Forskningsstøtte og konsulenthonorar fra OrtoMedic, forskningsstøtte og konsulenthonorar fra Biomet Norge og forskningsstøtte fra Smith \& Nephew. Ragnhild Øydna Støen: Kongresstøtte fra Nycomed.

\section{Litteratur}

1. Lofthus CM, Frihagen F, Meyer HE et al. Epidemiology of distal forearm fractures in Oslo, Norway. Osteoporos Int 2008; 19: 781-6.

2. Lofthus CM, Osnes EK, Falch JA et al. Epidemiology of hip fractures in Oslo, Norway. Bone 2001; 29: 413-8.

3. Joakimsen RM, Berntsen GK, Fønnebø V. Brudd i ryggen - et stort helseproblem for eldre kvinner? Tidsskr Nor Lægeforen 2001; 121: 598-602.

4. Gjertsen JE, Engesaeter LB, Furnes 0 et al. The Norwegian Hip Fracture Register: experiences after the first 2 years and 15,576 reported operations. Acta Orthop 2008; 79: 583-93.

5. Frihagen F. On the diagnosis and treatment of femoral neck fractures. Acta Orthop Suppl 2009; 80: $1-26$

6. Frihagen F, Nordsletten L, Madsen JE. Hemiarthroplasty or internal fixation for intracapsular dis placed femoral neck fractures: randomised controlled trial. BMJ 2007; 335: 1251-4.

7. Figved W, Opland V, Frihagen F et al. Cemented versus uncemented hemiarthroplasty for displaced femoral neck fractures. Clin Orthop Relat Res 2009; 467: 2426-35

8. Heetveld MJ, Rogmark C, Frihagen F et al. Internal fixation versus arthroplasty for displaced femoral neck fractures: what is the evidence? J Orthop Trauma 2009; 23: 395-402.

9. Lofthus CM, Osnes EK, Meyer HE et al. Young patients with hip fracture: a population-based study of bone mass and risk factors for osteoporosis. Osteoporos Int 2006; 17: 1666-72.

10. Gjertsen JE, Vinje T, Engesaeter LB et al. Internal screw fixation compared with bipolar hemiarthroplasty for treatment of displaced femoral neck fractures in elderly patients. J Bone Joint Surg Am 2010; 92: 619-28

11. Meyer HE, Tverdal A, Falch JA et al. Factors associated with mortality after hip fracture. Osteoporos Int 2000; 11: 228-32.

12. Parker M, Johansen A. Hip fracture. BMJ 2006; 333: $27-30$

13. Frihagen F, Nordsletten L, Tariq R et al. MRI diagnosis of occult hip fractures. Acta Orthop 2005; 76: 524-30

14. Parker MJ, Raghavan R, Gurusamy K. Incidence of fracture-healing complications after femoral neck fractures. Clin Orthop Relat Res 2007: 458: 175-9.

15. Hay D, Parker MJ. Hip fracture in the immobile patient. J Bone Joint Surg Br 2003; 85: 1037-9. 
16. Cserhati P, Kazar G, Manninger J et al. Nonoperative or operative treatment for undisplaced femoral neck fractures: a comparative study of 122 non-operative and 125 operatively treated cases. Injury 1996: 27: 583-8.

17. Jensen J, Hogh J. Fractures of the femoral neck. A follow-up study after non-operative treatment of Garden's stage 1 and 2 fractures. Injury 1983; 14: $339-42$.

18. Parker MJ, Stockton G. Internal fixation implants for intracapsular proximal femoral fractures in adults. Cochrane Database Syst Rev 2001; nr.4: CD001467.

19. Gurusamy K, Parker MJ, Rowlands TK. The complications of displaced intracapsular fractures of the hip: the effect of screw positioning and angulation on fracture healing. J Bone Joint Surg $\mathrm{Br}$ 2005; 87: 632-4

20. Rogmark C, Johnell 0 . Primary arthroplasty is better than internal fixation of displaced femoral neck fractures: a meta-analysis of 14 randomized studies with 2,289 patients. Acta Orthop 2006; 77 : 359-67.

21. Blomfeldt R, Törnkvist $H$, Eriksson $K$ et al. A randomised controlled trial comparing bipolar hemiarthroplasty with total hip replacement for displaced intracapsular fractures of the femoral neck in elderly patients. J Bone Joint Surg Br 2007; 89: $160-5$.

22. Parker MJ, Khan RJ, Crawford J et al. Hemiarthroplasty versus internal fixation for displaced intracapsular hip fractures in the elderly. A randomised trial of 455 patients. J Bone Joint Surg Br 2002; 84: $1150-5$

23. Parker MJ, Gurusamy K. Internal fixation versus arthroplasty for intracapsular proximal femoral fractures in adults. Cochrane Database Syst Rev 2006; nr.4: CD001708.

24. Bhandari M, Devereaux PJ, Swiontkowski MF et al. Internal fixation compared with arthroplasty for displaced fractures of the femoral neck. A metaanalysis. J Bone Joint Surg Am 2003; 85-A: 1673-81.

25. Zlowodzki M, Brink O, Switzer J et al. The effect of shortening and varus collapse of the femoral neck on function after fixation of intracapsular fracture of the hip: a multi-centre cohort study. J Bone Joint Surg Br 2008; 90: 1487-94.

26. Rogmark C, Flensburg L, Fredin H. Undisplaced femoral neck fractures - no problems? A consecutive study of 224 patients treated with internal fixation. Injury 2009; 40: 274-6.

27. Damany DS, Parker MJ, Chojnowski A. Complications after intracapsular hip fractures in young adults. A meta-analysis of 18 published studies involving 564 fractures. Injury 2005; 36: 131-41.

28. Berry DJ, von Knoch M, Schleck CD et al. Effect of femoral head diameter and operative approach on risk of dislocation after primary total hip arthroplasty. J Bone Joint Surg Am 2005; 87 : 2456-63.

29. Parker MJ, Gurusamy K. Arthroplasties (with and without bone cement) for proximal femoral fractures in adults. Cochrane Database Syst Rev 2006; nr. 3: CD001706

30. Ahn J, Man LX, Park S et al. Systematic review of cemented and uncemented hemiarthroplasty outcomes for femoral neck fractures. Clin Orthop Relat Res 2008; 466: 2513-8.

31. Learmonth ID, Young C, Rorabeck C. The operation of the century: total hip replacement. Lancet 2007; 370: $1508-19$
32. Parvizi J, Holiday AD, Ereth MH et al. The Frank Stinchfield Award. Sudden death during primary hip arthroplasty. Clin Orthop Relat Res 1999; nr. 369: 39-48.

33. Blomfeldt R, Törnkvist H, Ponzer S et al. Comparison of internal fixation with total hip replacement for displaced femoral neck fractures. Randomized controlled trial performed at four years. J Bone Joint Surg Am 2005; 87: 1680-8.

34. Blomfeldt R, Törnkvist H, Ponzer S et al. Internal fixation versus hemiarthroplasty for displaced fractures of the femoral neck in elderly patients with severe cognitive impairment. J Bone Joint Surg $\operatorname{Br} 2005$; 87: 523-9.

35. Johansson T, Jacobsson SA, Ivarsson I et al. Internal fixation versus total hip arthroplasty in the treatment of displaced femoral neck fractures: a prospective randomized study of 100 hips. Acta Orthop Scand 2000; 71: 597-602

36. Rogmark C, Carlsson A, Johnell $O$ et al. A pro spective randomised trial of internal fixation versus arthroplasty for displaced fractures of the neck of the femur. Functional outcome for 450 patients at two years. J Bone Joint Surg Br 2002; 84: 183-8.

37. Keating JF, Grant A, Masson M et al. Randomized comparison of reduction and fixation, bipolar hemiarthroplasty, and total hip arthroplasty. Treatment of displaced intracapsular hip fractures in healthy older patients. J Bone Joint Surg Am 2006; 88: 249-60.

38. Ravikumar KJ, Marsh G. Internal fixation versus hemiarthroplasty versus total hip arthroplasty for displaced subcapital fractures of femur - 13 year results of a prospective randomised study. Injury 2000; 31: 793-7.

39. Neander G, Adolphson P, von Sivers K et al. Bone and muscle mass after femoral neck fracture. A controlled quantitative computed tomography study of osteosynthesis versus primary total hip arthroplasty. Arch Orthop Trauma Surg 1997; 116: 470-4.

40. van Dortmont LM, Douw CM, van Breukelen AM et al. Cannulated screws versus hemiarthroplasty for displaced intracapsular femoral neck fractures in demented patients. Ann Chir Gynaecol 2000; 89: $132-7$.

41. Puolakka TJ, Laine HJ, Tarvainen T et al. Thompson hemiarthroplasty is superior to Ullevaal screws in treating displaced femoral neck fractures in patients over 75 years. A prospective randomized study with two-year follow-up. Ann Chir Gynaecol 2001; 90: 225-8.

42. Søreide O, Mølster A, Raugstad TS. Internal fixation versus primary prosthetic replacement in acute femoral neck fractures: a prospective, randomized clinical study. Br J Surg 1979; 66: 56-60

43. Sikorski JM, Barrington R. Internal fixation versus hemiarthroplasty for the displaced subcapital fracture of the femur. A prospective randomised study. J Bone Joint Surg Br 1981; 63-B: 357-61.

44. Jonsson B, Sernbo I, Carlsson A et al. Social func tion after cervical hip fracture. A comparison of hook-pins and total hip replacement in 47 patients. Acta Orthop Scand 1996: 67: 431-4.

45. Davison JN, Calder SJ, Anderson GH et al. Treatment for displaced intracapsular fracture of the proximal femur. A prospective, randomised trial in patients aged 65 to 79 years. J Bone Joint Surg Br 2001: 83: 206-12.

46. Jensen J, Rasmussen T, Christensen $\mathrm{S}$ et al. Internal fixation or prosthetic replacement in fresh femoral neck fractures. Acta Orthop Scand 1984; 55: 712

47. Roden M, Schon M, Fredin H. Treatment of displaced femoral neck fractures: a randomized minimum 5-year follow-up study of screws and bipolar hemiprostheses in 100 patients. Acta Orthop Scand 2003; 74: $42-4$

48. Svenningsen S, Benum P, Nesse 0 et al. Lårhalsbrudd hos eldre. En sammenlikning av tre behandlingsmetoder. Tidsskr Nor Lægeforen 1985; 105 : 492-5.

49. van Vugt AB, Oosterwijk WM, Goris RJ. Osteosynthesis versus endoprosthesis in the treatment of unstable intracapsular hip fractures in the elderly. A randomised clinical trial. Arch Orthop Trauma Surg 1993; 113: 39-45.

50. Skinner P, Riley D, Ellery J et al. Displaced subcapital fractures of the femur: a prospective randomized comparison of internal fixation, hemiarthroplasty and total hip replacement. Injury 1989; 20: $291-3$.

51. Gjertsen JE, Lie SA, Fevang JM et al. Total hip replacement after femoral neck fractures in elderly patients : results of 8,577 fractures reported to the Norwegian Arthroplasty Register. Acta Orthop 2007; 78: 491-7.

52. Baker RP, Squires B, Gargan MF et al. Total hip arthroplasty and hemiarthroplasty in mobile, independent patients with a displaced intracapsular fracture of the femoral neck. A randomized, controlled trial. J Bone Joint Surg Am 2006; 88: 2583-9.

53. Harrington KD. Orthopedic surgical management of skeletal complications of malignancy. Cancer 1997; 80: 1614-27.

54. Handoll HH, Farrar MJ, McBirnie J et al. Heparin, low molecular weight heparin and physical methods for preventing deep vein thrombosis and pulmonary embolism following surgery for hip fractures. Cochrane Database Syst Rev 2000; nr. 2: CD000305

55. Parker MJ, Handoll HH, Griffiths R. Anaesthesia for hip fracture surgery in adults. Cochrane Database Syst Rev 2004; nr. 4: CD000521.

56. Juliebø V, Bjøro K, Krogseth M et al. Risk factors for preoperative and postoperative delirium in elderly patients with hip fracture. J Am Geriatr Soc 2009; 57: 1354-61.

57. Siegmeth AW, Gurusamy K, Parker MJ. Delay to surgery prolongs hospital stay in patients with fractures of the proximal femur. J Bone Joint Surg Br 2005; 87: 1123-6.

58. Weller I, Wai EK, Jaglal S et al. The effect of hospital type and surgical delay on mortality after surgery for hip fracture. J Bone Joint Surg Br 2005; 87: $361-6$.

59. Orosz GM, Hannan EL, Magaziner J et al. Hip fracture in the older patient: reasons for delay in hospitalization and timing of surgical repair. J Am Geriatr Soc 2002; 50: 1336-40.

60. Orosz GM, Magaziner J, Hannan EL et al. Association of timing of surgery for hip fracture and patient outcomes. JAMA 2004; 291: 1738-43.

61. Speed K. The classic. The unsolved fracture: Kellogg Speed, M. D., F. A. C. S. Clin Orthop Relat Res 1980; 152: 3-9.

Manuskriptet ble mottatt 21.10. 2009 og godkjent 6.5. 2010. Medisinsk redaktør Åslaug Helland. 